\title{
Social playware for mediating tele-play interaction over distance
}

\author{
Lund, Henrik Hautop; Thorsteinsson, Tumi
}

Published in:

Artificial Life and Robotics

Link to article, DOI:

10.1007/s10015-011-0995-8

Publication date:

2012

Document Version

Publisher's PDF, also known as Version of record

Link back to DTU Orbit

Citation (APA):

Lund, H. H., \& Thorsteinsson, T. (2012). Social playware for mediating tele-play interaction over distance.

Artificial Life and Robotics, 16(4), 435-440. https://doi.org/10.1007/s10015-011-0995-8

\section{General rights}

Copyright and moral rights for the publications made accessible in the public portal are retained by the authors and/or other copyright owners and it is a condition of accessing publications that users recognise and abide by the legal requirements associated with these rights.

- Users may download and print one copy of any publication from the public portal for the purpose of private study or research.

- You may not further distribute the material or use it for any profit-making activity or commercial gain

- You may freely distribute the URL identifying the publication in the public portal

If you believe that this document breaches copyright please contact us providing details, and we will remove access to the work immediately and investigate your claim. 


\section{Social playware for mediating tele-play interaction over distance}

\begin{abstract}
We suggest that novel playware technology can function as a mediator for playful social interaction over long distances, such as where people are separated by physical distance but feel the presence of each other mediated through their interaction with the playware technology. In order to investigate such social playware, we developed the Playware Soccer game and tested it with more than 1000 users during the FIFA World Cup 2010 in South Africa. The test was conducted in townships, orphanages for HIV/AIDS children, markets, FIFA fan parks, etc., along with simultaneous tests with similar set-ups in Europe and Asia. With the social playware, players would compete against each other simultaneously in three continents, Africa, Europe, and Asia, and feel the presence of the competitors on the other continents expressed through the playware. The playware game is set up to motivate players to engage in training in technical soccer skills by receiving immediate feedback and offering challenges to players of all skills at soccer. It is played on a modular interactive wall composed of modular interactive tiles that respond with colored lights, sounds, and scores of the players' performance. This article outlines the concept of social playware and physical-virtual tele-play, and exemplifies this with the playware soccer game.
\end{abstract}

Key words Social playware - Modular robotics · Tele-play · Soccer

\section{Social playware}

Playware is defined as intelligent hardware and software that creates play, and playful experiences, for users of all

H.H. Lund $(\bowtie) \cdot T$. Thorsteinsson

Center for Playware, Technical University of Denmark, Building 325,

2800 Kgs. Lyngby, Denmark

e-mail: hhl@playware.dtu.dk

This work was presented in part at the 16th International Symposium on Artificial Life and Robotics, Oita, Japan, January 27-29, 2011 ages. ${ }^{1}$ In this article, we suggest that novel playware technology can function as a mediator for playful social interaction over long distances, where people are separated by physical distance but feel the presence of each other mediated through their interaction with the playware technology. Often, human-machine interaction is viewed as a 1-to-1 interaction between an individual human being and a technological artifact. A lot of research in the fields of human-robot interaction, socially intelligent robotics, and human-computer interaction has focused on individual relationships and interactions with the technology (e.g., Breazeal ${ }^{2}$ and Fong et al. $^{3}$ ). In many cases, the creation of playful technology, e.g., robotic toys and interactive playgrounds, has taken its inspiration from such human-machine interaction research. Based on this development, the research community has also gained knowledge on how the individual interacts and plays with such playware products (e.g., Billard ${ }^{4}$ and Resnick et al. ${ }^{5}$ ).

In our view, it is important to expand playware research to focus on social interactions, so that the starting point for research and development becomes the social interaction mediated by the technology rather than the individual interaction mediated by the technology. We can define social playware as follows: social playware is playware which aims at creating playful social interactions between several users.

Such playful social interaction can, for instance, be play between children in a kindergarten mediated by an interactive playground, multiplayer games with a physical game platform such as Nintendo Wii, or the interaction of a team of elderly people performing games for the good of their health, e.g., with Dance Revolution. In all cases this is a free activity that the users engage in for the pleasure of play and social interaction itself. Hence, this is in accordance with the definition of play, which can be defined as follows: "Play is actions which we undertake and participate in with the purpose of creating a reality sphere within which we are free and can independently create and regulate moods (physical and mental states of tension) which provide us with specific, wanted experiences (of delight), both socially and individually". ${ }^{6}$ This definition underlines the point that play is undertaken by our own free will; human beings play because 
they want to play. At the same time, it underlines the fact that in the act of playing, we manage our lives by our own choice, as we create a special form of lived life outside "regular" life, where (lust for) life and happiness are the essence of play rules. By building on this definition of play, the aim of social playware simply focuses on the human desire to engage in social interactions and to live as a social being. It can therefore also be argued that social playware is included in the term "playware." Indeed, we view social playware as a subdiscipline of playware. However, this allows the research community to focus directly on the social interactions mediated by playware, and thereby provide a further understanding of how to create social interactions that are playful and which the users engage in for the pleasure of the social interaction.

We will exemplify social playware in this work with physical-virtual tele-play, which allows users to engage in social interactions over a distance mediated by the playware technology. In such a case, we can view the playware technology as mediating a playful tele-presence between people each interacting with their own playware tool, through which they sense the presence of the other people (in essence, presence removes the impression of mediation from a mediated experience). Examples of tele-play and social playware are seen in the form of massive multiplayer online games (MMOG), which are multiplayer video games which are capable of supporting hundreds or thousands of people playing together simultaneously over the Internet. However, such games do not allow for extensive physical and natural interactions (other than, for example, pressing the keyboard and speaking). Some physical interaction is promoted by some multiplayer online games, e.g., in the Japanese and Korean arcade halls, in the form of interactions with game cards (e.g., soccer cards). For a more natural and physical interaction, tele-presence has been studied intensively in studies of human-like presence using tele-operated androids. ${ }^{7,8}$ Such studies have promoted human-like technology to study presence, and some large videoconferencing set-ups have allowed for soccer tele-play. ${ }^{9} \mathrm{We}$, on the other hand, have made a first step in a much simpler yet playful technology for mediating social interaction. This is along the lines of the simple yet effective FeelLight technology for mediating social interaction by Suzuki and Hashimoto. ${ }^{10}$ Hence, we studied tele-presence without a large and bulky infrastructure, and without any anthropomorphic expression, but with an expression of simple light patterns, sounds, and scores. In a specific example, we made social playware connecting players in Asia, Africa, and Europe in a soccer game with playware technology in the form of modular interactive tiles.

\section{Playware soccer}

During the FIFA World Cup 2010, we ran a RoboSoccer World Cup in Asia, Europe, and Africa, amongst other places, in townships, orphanages for HIV/AIDS children, markets, etc. in South Africa. As an example of playware, the game was set up to motivate players to engage in technical soccer skills training by receiving immediate feedback, and to challenge players at different levels in soccer playing on a modular interactive wall composed of modular interactive tiles that respond with colored lights, sounds, and scores on the players' performance. The soccer game was developed together with professional soccer players Laudrup and Høgh to promote playful soccer skills. For the test conducted during the World Cup tournament, the soccer wall was composed of $3 \times 4$ modular interactive tiles. It is a distributed system, as each tile has its own processor, battery, and communication to neighboring tiles. The distributed nature of the system aimed at allowing the system to be easily set up and taken down within minutes anywhere and by anyone. Indeed, the flexibility obtained with a modular and distributed processing system should provide the opportunity to bring the new playware technology out to any township, market, or village in Africa and on other continents, since there is no need for any physical infrastructure whatsoever.

Often, other technological systems for physical interactions are characterized by being based on a centralized processing system, making the systems of fixed sized (and sometimes large and bulky), and/or they are characterized by their demand for some kind of infrastructure, e.g., electricity, access to a screen/projector, or similar. Examples include Lightspace, Makoto, Sportswall, and even DanceDance Revolution, with more participants, which need to have a centralized control station. This makes it somewhat difficult to apply the traditional technology for any user anywhere, since in many places in the world, the necessary infrastructure is not readily available to allow such technology to be applied. For example, this is the case for many places in Africa, and even in a comparably well-developed country like South Africa, where the FIFA World Cup 2010 was held, there are townships with no electricity (Fig. 1).

If, on the other hand, we take as the point of departure for our technology design that no infrastructure is available, it will lead to technology that is free from infrastructure demands and which can therefore be applied and used anywhere. It gives the possibility of bringing the technology to anybody anywhere, and thereby helps in contextualizing

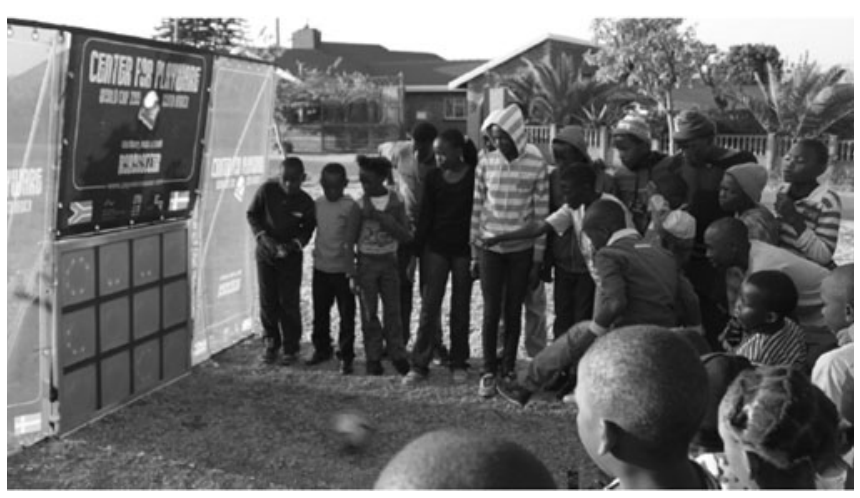

Fig. 1. Playware soccer in the township of Atteridgeville, South Africa, during the FIFA World Cup 2010 
both technology development and education in developing countries. The advantages of such a technological outcome may not be limited to the developing parts of the world. The freedom from infrastructure requirements may also have an important impact on the distribution and use of technological solutions in the developed areas of the world (e.g., for home care in the private homes of elderly people). Even in a private garden or on a football training field in the developed world the necessary infrastructure, such as electricity outlets or computer monitors, may not necessarily be available. Therefore, it is interesting to research the flexibility of modular playware in allowing the technology to be set up and used anywhere within minutes.

Hence, the playware soccer game was developed with a modular interactive tiles system, ${ }^{11}$ which is an example of modular playware. ${ }^{12}$ The system is composed of a number of modular interactive tiles which can be attached to each other to form the overall system. Each modular interactive tile has a quadratic shape measuring $300 \mathrm{~mm} \times 300 \mathrm{~mm} \times$ $33 \mathrm{~mm}$. It includes an ATmega 1280 as the main processor in each tile, and each tile can communicate by infrared (IR) to its four neighboring tiles. Each side of a tile is made in a jigsaw puzzle pattern (Fig. 2) to provide opportunities for the tiles to be attached to each other. A force-sensitive resistor (FSR) is mounted as a sensor on the center of a raised platform underneath the cover. This allows an analogue measurement of the force exerted on the top of the cover.

A 2-axis accelerometer $(5 \mathrm{G})$ is mounted on a PCB to detect the horizontal or vertical placement of the tile. Eight RGB light-emitting diodes (LED SMD 1206) are mounted at equal intervals in a circle on the PCB so that they can light up underneath the transparent Satin Ice circle.

The modular interactive tiles are battery-powered individually and are rechargeable. There is a Li-Io polymer (rechargeable) battery on top of the PCB. A fully charged modular interactive tile can run continuously for approximately $30 \mathrm{~h}$ and takes $3 \mathrm{~h}$ to recharge. On the PCB, there are connectors to mount an XBee radio communication chip. Hence, there are two types of tiles, those with a radio communication chip (master tiles) and those without (slave tiles). The master tile may communicate with a game selector box (game card reader) and initiates the games on the built platform. Every platform has to have at least one master tile if communication is needed, e.g., to a game selector box or a PC.

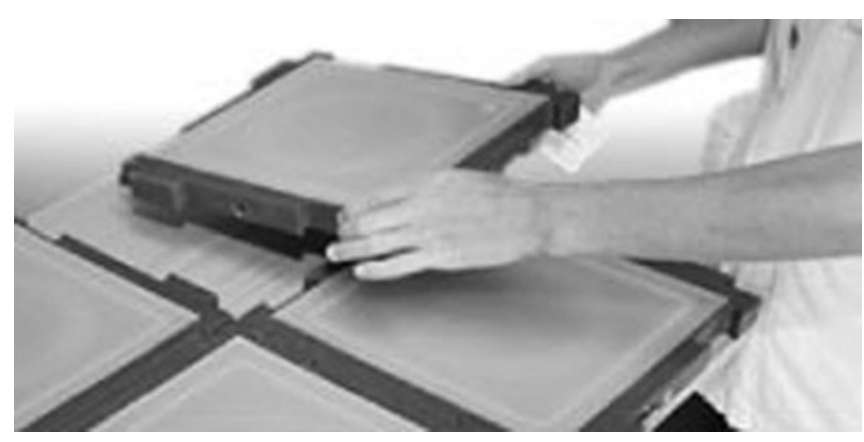

Fig. 2. Assembly of the modular interactive tiles as a jigsaw puzzle
With this specification, a system composed of modular interactive tiles is a fully distributed system, where each tile contains processing (ATmega 1280), its own energy source (Li-Io polymer battery), sensors (FSR sensor and 2-axis accelerometer), effectors (8 color LEDs), and communication (IR transceivers, and possibly an XBee radio chip). In this respect, each tile is self-contained and can run autonomously. However, the overall behavior of a system composed of such individual tiles is the result of the assembly and coordination of all the tiles.

\section{Connectivity}

In order to develop tele-play for social interaction it is important that the physical interactive platforms can communicate with each other, both locally and globally, so that social interaction can be mediated through the playware.

\subsection{Local connection}

To create local communication between physically separated groups of modular interactive tiles, and between a group of tiles and a PC, we used the XBee with the ZigBee radio communication protocol. In each group of tiles there is one tile (master tile) with the XBee radio communication chip. This tile can collect and send information. The information can thereby be communicated between two "islands" of tiles, i.e., between the master in one island and the master in another island. For communication to and from a host computer, we designed an XBee USB dongle to be connected to the host computer, which can then communicate with the master tile using the same protocol.

\subsection{Global connection}

With local communication allowing easy communication between tiles and a host computer, e.g., a laptop/netbook, we were able to relay global communication over laptops connected to the internet, e.g., laptops with a $3 \mathrm{G}$ wireless connection, so that the tele-play could happen on platforms that communicate with each other over the Internet. A Java program was designed to run on the laptop, which was connected to the tiles with the XBee. The Java program kept track of the hits on the tiles, played feedback sounds, showed the time and score of the game at run-time, and kept the total score of each game. At the end of each game, the program sent information to a web-site that saved it, together with a username, password, and location, on a high score list which was updated immediately. The high score list updates would be visible on internet-connected computers at different locations, anywhere globally, at run time.

With the design of both local and global connectivity, it is possible to create both local and global physically interactive games. The local connectivity was used to create feedback from a local host computer in the form of time and score displayed on a monitor, and sound from a loudspeaker 
connected to the host computer. The global connectivity was used to allow feedback in the form of run-time score updates in competitions between users playing the same physically interactive game in different parts of the world, i.e., allowing for social interaction over distance.

\section{Soccer game}

The content of the game was crucial to ensure soccer skills training in a playful manner, so we collaborated with professional soccer players Laudrup and $\mathrm{H} \varnothing \mathrm{gh}$ in order to create an appropriate game using just $3 \times 4$ tiles. In a soccer game, a specific number of tiles light up in different colors. Each of them counts down with their eight LEDs. The player has to hit the tile before the LEDs are all turned off, and gets points for how many LEDs are turned on at hit time, and these points are multiplied by a factor of 1,2 , or 3 depending on how high the tile is positioned (row 1,2, or 3). Also, at a random time, the LEDs of one of the tiles will make a fast spinning pattern, indicating that if that tile is hit a bonus round will be initiated, during which the player can gain extra points by hitting the tile that is lit up.

Preliminary tests with a number of adult players showed that the soccer game could be set to an appropriate level of difficulty that was both easy enough for all the people in the test to play and difficult enough that all would be challenged to obtained a higher score. This difficulty level was set experimentally by investigating the time needed for people to kick the ball and hit a tile, in order to set the LED countdown time to an appropriate level (the time used from the moment when all 8 LEDs were turned on until all LEDs were turned off, and then the light would jump to another tile).

\section{Layered multimodal feedback}

To enhance the system as social playware and to increase the motivation to play the game, we designed an immediate multimodal feedback so that the player would not only receive immediate feedback directly from the tiles in terms of the changing colored lights, but also sound feedback and graphical feedback in terms of the time and score via a host computer.. When a player hit a lit tile, the light on that tile would turn off and jump to another tile, a sound would be played from a loudspeaker, and the increase in score would be shown on a monitor. When the game ended, the position on the high score list would be shown on a monitor.

It should be noted that the game was designed so that it could run as an interesting game even without these additional feedback modalities. Both the additional immediate (sound, score, time) and delayed (local high score list and global high score list) feedback modalities can be added as layers on top of the basic game that runs on the modular interactive tiles only (Fig. 3). Hence, with this layered design of feedback modalities, it is possible (i) to run the game as a simple game with only the lowest level of feedback
Layer Platform

5

Internet
3

2

1

Tiles
PC monitor

PC monitor

PC loudspeaker Sound

Light

Fig. 3. The layered multimodal feedback design for the playware soccer game

(colored lights) on the modular interactive tiles, (ii) to run it with higher levels of feedback (sound, score, time) by adding a laptop PC, or (iii) to run it with the highest level of feedback (global high score list) by adding an internet connection. This third option was used for the tele-play experiments to create the soccer game as a social playware.

The layered structure in the design of feedback modalities may resemble the layered design in much behaviorbased robotic engineering. ${ }^{13}$ For instance, the original subsumption architecture by Brooks ${ }^{14}$ states that behaviors can be designed to run in parallel on top of each other, starting from the design of the simplest behaviors. Once the simplest behavior is designed, implemented, and debugged, this behavior can run by itself, and another behavior can be designed, implemented, and debugged to run in parallel on top of the simplest behavior, and so forth. The design continues with layers of behavior on top of the previous ones that all run in parallel, and the lower levels continue to function as originally designed. The design of multimodal feedback, which we propose here, works on the same principle. First, a simple feedback is designed which can run by itself, and then new layers of feedback can be added on top to run in parallel. In the present case of the soccer game, the simplest feedback is designed to be the change of light on the modular interactive tiles when a tile is hit. Once this feedback modality was designed, implemented, and debugged, on top of this, we designed, implemented, and debugged the sound modality, which would run in parallel with the light feedback. Then on top of this we designed, implemented, and debugged the time and score feedback from a monitor. On top of this, we added the local high score list feedback, and on top of this, we designed, implemented, and debugged the global high score list.

As with the original subsumption architecture, where different behavior modules can run on different time scales, 
so with this layered multimodal feedback design the different layers may run on different time scales, with the lower levels being executed with the fastest feedback time cycle and the highest levels with the slowest feedback time cycle. The lower level behaviors/feedback modalities need to show a very fast response for the system to work, whereas the higher level behaviors/feedback modalities can show a response at greater intervals.

The advantage of this layered multimodal feedback design is that it is possible to create simple layers of feedback that can run by themselves and work in their own right, and then add new layers to run in parallel on top of the previously designed layers. When the user is executing the system, it is possible to add/remove layers (feedback modalities) from the top. Essentially, this adding and removing of new feedback modalities can even be done at run-time, since the lower levels will keep running and working whatever is added on top of them. This gives great flexibility to the system for both the designer and the user.

\section{Tests}

In order to explore social playware and the potential of such playware to mediate social interaction, we needed to test a broad range of cultural differences in both users and environments. Therefore, we tested the system simultaneously in Denmark (Europe), South Africa (Africa), and Japan (Asia) during the FIFA World Cup 2010. For instance, in Asia the system was tested in highly metropolitan areas such as in Shibuya, Tokyo, whereas in South Africa we tested it in a variety of places, including an orphanage, numerous townships, a public market, a village, an official FIFA fan park, a science discovery center, a university, a fan bar, a public park in Soweto, etc. This variety of places was selected in order to ensure the broadest possible test in terms of variation in the environment, social status, age group, educational level, technology interest, and the soccer interest of the users. Indeed, users were from 3 years old to 80 years old (Fig. 4), they were from orphanages with children from families with HIV/AIDS to adult soccer fans

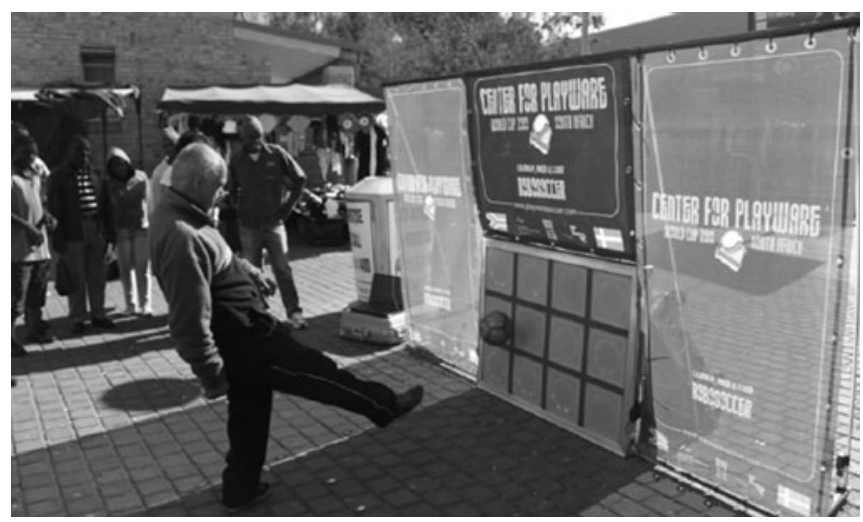

Fig. 4. An older man playing the playware soccer at a taxi rank in Randburg, South Africa from high-income areas, and they ranged from people with no education to people with a university degree.

The system was designed for flexibility in the modular interactive tiles and the layered multimodal feedback design, which together aimed at creating a system that could be set up and used by anybody anywhere within minutes. The modular interactive tiles can be viewed as providing the hardware building blocks, while the layered multimodal feedback design provides feedback building blocks, and the simple construction with these building blocks gives a high degree of flexibility for the designer and the user to create various set-ups and interaction possibilities in an easy manner.

In total, the system was tested with more than 1000 users during the FIFA World Cup 2010. The distributed nature of the system (each tile with its own processor, battery, and communication to neighboring tiles) allowed it to be set up and taken down easily. Indeed, the flexibility obtained with the modular and distributed processing system gave the opportunity of bringing the new playware technology to any township, market, and village in Africa, since there was no need for any physical infrastructure whatsoever. It proved possible to set the system up very quickly on the ground in townships such as Soweto and Atteridgeville, in public parks in Soweto, markets and a bus station in Randburg, and in remote villages such as Phokeng. In some places, the system was run with only part of the layered multimodal feedback, and in other places it was run with all layers active. The layered multimodal feedback allowed a set-up with just layer 1 in some places, or layers 1-4 in other places, while some places ran the full system with layers 1-5 (including a global high score list via an Internet connection (Fig. 5)). Therefore, the system proved flexible enough to fit the time available, the local use, and the aim of the game at a particular place with a particular set of users.

When running the system with all five layers and in different locations at the same time, the system became a social playware which mediated social interaction over a long

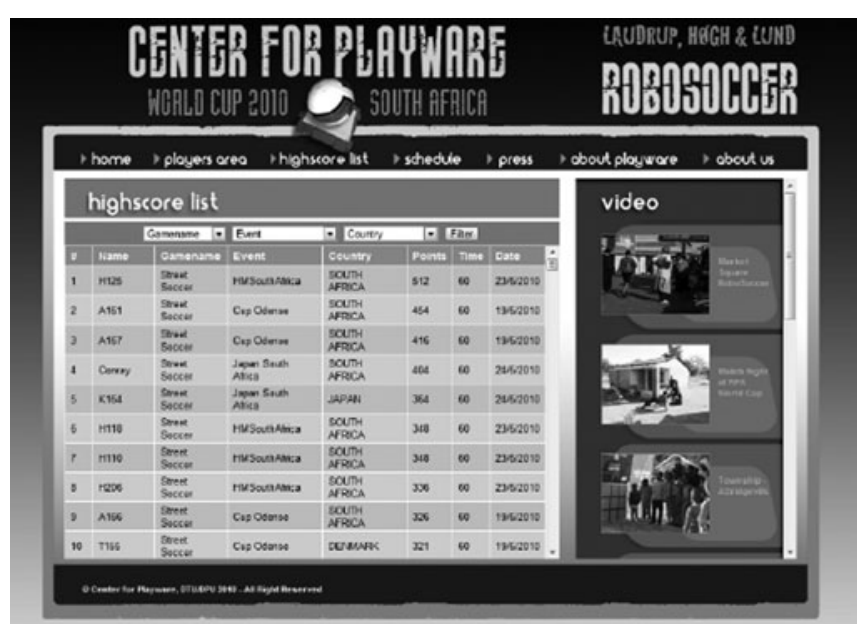

Fig. 5. The global high score list on the internet (www.playwaresoccer. com) 
distance. Most often, the social interaction would happen around a single set-up, e.g., in a township or market, with lots of people gathering around cheering, helping, and interacting socially around the playware and the individual player (see Fig. 1). So it was evident from the test observations that even with the playware soccer set-up utilizing only the lower layers of feedback modality, it became a social playware. However, this was reinforced to a large degree when the game was set up with all five layers and run in parallel at different locations, e.g., simultaneously in the small village of Phokeng in South Africa and in Shibuya in the center of Tokyo in Japan. In such cases, the players were observed to engage in a competition over distance: in one location (on one continent) they would see the scores of players in the other location (on another continent) playing with the playware soccer. The players would experience the high score list change minute by minute depending on the score at their own location and the score at the other location (visualized and continuously updated on the monitor next to the playware soccer set-up). In all cases, players engaged immediately in trying to get higher scores than the other location, and cheering and shouts related to the scores of the remote location on the other continent allowed us to observe the emotional engagement and social bonding both locally around the game, player, and audience, and also between the remote competitors who were invisible and unknown to each other.

\section{Discussion and conclusions}

As a test of our social playware, during the FIFA World Cup 2010, we ran a RoboSoccer World Cup in Asia, Europe, and Africa, most notably in townships, orphanages for HIV/ AIDS children, markets, etc. in South Africa. We linked the events together with a novel kind of physical-virtual live competition, which can be termed tele-play, and which as a social playware mediated social interactions. The tele-play took place between people in these African environments and metropolitan fans in larger cities in the developed world, e.g., in Tokyo, thereby trying to create a social bond and feeling between the fans world-wide during the World Cup through the physical-virtual tele-play. The social bonding was mediated through the physical football game between players on different continents who, at the same time and through tele-play with social playware, can compete directly and physically between continents.

The flexibility of the modular interactive tiles and the layered multimodal feedback design allowed the creation of a system that could be set up and used by anybody anywhere within minutes, and it was therefore possible to test the system with more than 1000 users during the FIFA World Cup 2010. Videos of some tests are available at: www. playwaresoccer.com

In general, the advantages of the proposed modular social playware can be summarized as a flexible set-up, independence in context, run-time feedback, competition as a motivation factor, framing of the game (World Cup soccer where one country wants to beat another country), and an audience-friendly game through sounds and score which can be followed by the audience, and where the audience can take on roles and feel part of the game (cheering, collecting balls, indicate bonus rounds, etc.). Hence, the layered multimodal feedback in the playware set-up can mediate both local social interaction and global social interaction. The disadvantages of the set-up as proposed here are that this is not an in-game presence (the tele-presence is not immediate but delayed), and it is a single-player game, physical differences may mean that players are not competing an on equal footing (e.g., the physical status of the opponent on the other continent is unknown to the player). Another disadvantage of the study presented is that we only have "event-based" observations and no long-term observations. We will elaborate further on these issues and on social playware in general in future work.

Acknowledgments The work was performed with the help of colleagues at the Center for Playware, Technical University of Denmark, and the Danish School of Education (AU). Baldur Bjarnason, Niels Sandmann, Jacob Nielsen, Steffen Andersen, and Bjarke Pedersen made highly valuable contributions to the development, and Stine Ejsing-Duun to the concept discussions. Thanks also go to local organizers, including A. Smith, the Meraka Institute, B. Windram, Junior Engineers for Africa, the Royal Danish Embassy in Tokyo, Brian Laudrup, and Lars Høgh.

\section{References}

1. Lund HH, Klitbo T, Jessen C (2005) Playware technology for physically activating play. Artif Life Robotics 9(4):165-174

2. Breazeal C (2002) Designing sociable robots. MIT Press, Cambridge

3. Fong T, Nourbakhsh I, Dautenhahn K (2003) A survey of socially interactive robots. Robotics Auton Syst 42(3-4):143-166

4. Billard A (2003) Robota: clever toy and educational tool. Robotics Auton Syst 42:259-269

5. Resnick M, Martin F, Berg R, et al (1998) Digital manipulatives: new toys to think with. Proceedings of the CHI'98 Conference on Human Factors in Computing Systems, Los Angeles, April, pp 281-287

6. Jessen C, Lund HH. On play forces, play dynamics and playware. Unpublished manuscript

7. Ishiguro H (2006) Android science: conscious and subconscious recognition. Connect Sci 18(4):319-332

8. Sakamoto D, Kanda T, Ono T, et al (2007) Androids as a telecommunication medium with human-like presence. Proceedings of the 2nd ACM/IEEE International Conference on Human-Robot Interactions

9. Mueller F, Agamanolis A, Picard R (2003) Exertion interfaces: sports over a distance for social bonding and fun. Proceedings of CHI 2003, ACM, 5:1, pp 561-568

10. Suzuki K. Hashimoto S (2004) FeelLight: a communication device for distant nonverbal exchange. Proceedings of ETP'04, New York, ACM

11. Lund HH (2009) Modular robotics for playful physiotherapy. Proceedings of the IEEE International Conference on Rehabilitation Robotics, IEEE Press, New York, pp 571-575

12. Lund HH, Marti P (2009) Designing modular robotic playware. $18^{\text {th }}$ IEEE International Symposium on Robot and Human Interactive Communication (Ro-Man 2009), IEEE Press, New York, pp $115-121$

13. Arkin RC (1998) Behavior-based robotics. MIT Press, Cambridge

14. Brooks RA (1986) A robust layered control system for a mobile robot. IEEE J Robotics Autom 2(1):14-23 